\title{
Pemanfaatan Alumina Waste dari Tailing Bauksit Menjadi Zeolit Adsorben
}

\section{Utilization of Alumina Waste from Bauxite Tailing To Adsorbent Zeolite}

\author{
Sy. Indra Septiansyah*, Maya Santi \\ Jurusan Teknik Pertambangan Politeknik Negeri Ketapang \\ Jalan Rangga Sentap-Dalong, Ketapang, Kalimantan Barat, Indonesia, 78813 \\ *E-mail: indraqadrie@gmail.com
}

Naskah diterima: 16 November 2018, direvisi: 25 November 2018, disetujui: 30 November 2018

DOI: 10.17146/eksplorium.2018.39.2.4982

\begin{abstract}
ABSTRAK
Tailing bauksit merupakan produk samping yang berasal dari hasil benefisiasi bijih bauksit. Proses benefisiasi dilakukan dengan cara memisahkan partikel-partikel yang ada seperti lumpur atau clay, akar-akar, butiran bijih bauksit berkisar $2 \mathrm{~mm}$ yang dibuang atau menjadi waste product atau disebut sebagai limbah tailing. Tingginya kadar alumina dan silika dalam tailing bauksit menjadi salah satu alasan mengapa tailing ini dapat dimanfaatkan sebagai bahan dasar dalam pembuatan produk baru yaitu zeolit sintetis. Zeolit sintetis dipilih karena zeolit merupakan produk impor, harganya mahal dan memiliki sifat yang seragam serta $>150$ jenis zeolit sintetis dapat dibuat secara komersial dan bahkan di industri zeolit dapat dimanfaatkan secara luas sebagai adsorben, penukar ion, membrane, katalis, dan lain-lain. Hasil analisis kimia tailing bauksit menunjukkan komposisi: alumina $\left(\mathrm{Al}_{2} \mathrm{O}_{3}\right)$ sekitar $49,41 \%$, silika $\left(\mathrm{SiO}_{2}\right)$ sekitar $12,58 \%$, hematit $\left(\mathrm{Fe}_{2} \mathrm{O}_{3}\right)$ sekitar 10,6\% dan beberapa oksida anorganik lainnya dalam jumlah yang kecil. Proses konversi tailing bauksit menjadi zeolit adsorben dilakukan dengan metode fusi kaustik untuk mendapatkan ekstrak fusi (prekursor alumina) kemudian dilanjutkan dengan penambahan prekursor natrium silikat dengan formula sintesis $1,2 \mathrm{Na}_{2} \mathrm{O} .0,5 \mathrm{SiO}_{2} \cdot 0,5 \mathrm{Al}_{2} \mathrm{O}_{3} \cdot 10 \mathrm{H} 2 \mathrm{O}$. Kristalisasi produk dilakukan dengan menggunakan metode hidrotermal pada suhu rendah dengan variable waktu inkubasi yang ditentukan. Hasil penelitian menunjukkan bahwa sintesis tailing bauksit menggunakan fusi kaustik dan dilanjutkan dengan kristalisasi di temperatur rendah dan di bawah tekanan atmosferik telah berhasil mentransformasi produk dari fasa amorf gel menjadi produk fasa kristalin zeolit adsorben.
\end{abstract}

Kata Kunci: tailing bauksit, fusi kaustik, hidrotermal, adsorben, zeolit sintetis

\begin{abstract}
Bauxite tailings is a by products material derived from bauxite ore beneficiation. The beneficiation process is done by separating the particles that exist such as mud or clay, roots, bauxite ore grain ranges from $2 \mathrm{~mm}$ are discarded or be referred as a waste product or tailings. High concentration of alumina and silica in bauxite tailings are considered as one of the reasons why they can be used as base material in the making new products, namely synthetic zeolite. Synthetic zeolite is selected because zeolites are imported, expensive and have uniform properties and >150 types of synthetic zeolites can be made commercially and even in industrial zeolite can be used widely as an adsorbent, ion exchange, membranes, catalysts, etc. The chemical analysis of bauxite tailing showed the composition of alumina $\left(\mathrm{Al}_{2} \mathrm{O}_{3}\right)$ is approximately $49.41 \%$, while silica $\left(\mathrm{SiO}_{2}\right)$ and hematite $\left(\mathrm{Fe}_{2} \mathrm{O}_{3}\right)$ are about $12.58 \%$ and $10.6 \%$ respectively, and also some other inorganic oxides are in small amounts. The conversion process of bauxite tailings into zeolite is carried out by caustic fusion method to extract the fusion (alumina precursor) followed by the addition of sodium silicate precursor with synthesis formula $1.2 \mathrm{Na}_{2} \mathrm{O}$.0.5 $\mathrm{SiO}_{2} \cdot 0.5 \mathrm{Al}_{2} \mathrm{O}_{3} \cdot 10 \mathrm{H}_{2} \mathrm{O}$. Products crystallization is carried out by hydrothermal method at low temperature with specified variable incubation period. The results showed that the zeolite synthesis of bauxite tailings using caustic fusion and followed by crystallization at low temperature and under atmospheric pressure has succeeded in transforming the product from an amorphous phase to the crystalline phase product zeolite adsorbent.
\end{abstract}

Keywords: bauxite tailings, caustic fusion, hydrothermal, adsorbent, zeolite synthesis 


\section{PENDAHULUAN}

Bauksit merupakan bahan baku utama dalam proses bayer untuk memproduksi alumina $\left(\mathrm{Al}_{2} \mathrm{O}_{3}\right)$. Proses pengolahan bauksit menjadi produk olahan dilakukan dengan cara pencucian menggunakan water jet yang disemprotkan ke material untuk menghasilkan bauksit yang bersih dalam fraksi kasar atau disebut sebagai washed bauxite dengan kadar $55-65 \%$ [1]. Hasil pencuciannya akan menghasilkan produk samping berupa lumpur atau clay pada fraksi halus yang disebut sebagai tailing bauksit.

Baru-baru ini, tailing bauksit yang dihasilkan dari proses benefisiasi bauksit mulai diperhatikan karena semakin hari semakin banyak tailing yang dihasilkan akibat dari aktivitas benefisiasi bauksit. Untuk itu perlu pemikiran bagaimana tailing bauksit tersebut dapat dimanfaatkan dan diolah menjadi produk yang berguna misalnya sebagai produk bata tahan api (refractroty), bahan bangunan, bahan penyerap (adsorben), bahan alloy, PAC (poly aluminium chloride) atau flokulan dan zeolit sintetis [2-4].

Hasil analisis kimia tailing bauksit menunjukkan komposisi alumina $\left(\mathrm{Al}_{2} \mathrm{O}_{3}\right)$ sekitar 49,41\%, silika $\left(\mathrm{SiO}_{2}\right)$ sekitar $12,58 \%$, hematit $\left(\mathrm{Fe}_{2} \mathrm{O}_{3}\right)$ sekitar 10,06\% dan beberapa oksida anorganik lainnya dalam jumlah yang kecil. Tingginya kadar alumina dan silika dalam tailing bauksit menjadi salah satu alasan mengapa tailing ini dapat dimanfaatkan sebagai bahan dasar dalam pembuatan produk baru yaitu zeolit sintetis.

Saat ini penggunaan mineral zeolit semakin meningkat, mulai dari penggunaannya dalam industri kecil hingga dalam industri berskala besar. Negara maju seperti Amerika Serikat dan Jepang sudah benar-benar memanfaatkan zeolit dalam industri. Karena sifat-sifat yang dimiliki zeolit tersebut, maka mineral ini dapat dimanfaatkan dalam berbagai bidang pertanian dan industri kimia seperti sebagai katalis, ion exchange, dan adsorbent dalam pengolahan limbah. Namun, zeolit alam juga sudah banyak dimanfaatkan sehingga jumlahnya semakin berkurang. Selain itu mineral zeolit alam sulit dipisahkan dari batuan induknya. Mengingat begitu pentingnya peranan zeolit dalam kehidupan, maka perlu dilakukan usaha untuk mendapatkan zeolit dengan daya guna yang lebih baik dari zeolit alam. Untuk mengatasai semakin berkurangnya zeolit alam, maka telah dikembangkan zeolit sintetis yang memiliki kemampuan yang sama atau bahkan memiliki kemampuan yang lebih dari zeolit alam.

Zeolit sintetis adalah suatu senyawa kimia yang mempunyai sifat fisik dan kimia yang sama dengan zeolit yang ada di alam. Zeolit sintetis ini dibuat dari bahan baku dengan proses sintesis, yang dibuat sedemikian rupa sehingga menyerupai zeolit yang ada di alam. Beberapa ahli menamakan zeolit sintetis sama dengan nama mineral zeolit alam dengan menambahkan kata sintetis atau sintesis dibelakangnya. Dalam dunia perdagangan muncul nama-nama zeolit sintetis seperti zeolit-A, zeolit K-C, zeolit ZSM-5, zeolit X-Y dan lain-lain [5].

Transformasi tailing bauksit menjadi zeolit dapat dilakukan melalui berbagai macam metode dekomposisi. Zeolit pernah disentesis dengan menggunakan metode hidrotermal saja, namun hasilnya masih ditemukan pengotor kuarsa atau hidrosodalit yang cukup banyak [6]. Zeolit juga pernah disintesis dengan mengombinasikan metode fusi kaustik dan dilanjutkan dengan hidrotermal. Kombinasi ini menunjukkan bahwa produk zeolit hasil sintesis akan menghasilkan zeolit yang memiliki 
kemurnian cukup tinggi dan memiliki kinerja kapasitas tukar kation lebih baik dibandingkan dengan menggunakan metode hidrotermal saja. Pada penelitian ini akan dilakukan pembuatan zeolit adsorben dengan mengkombinasikan fusi kaustik sebagai tahapan metode untuk mendapatkan prekursor alumina dan silika yang berasal dari tailing bauksit, kemudian dilanjutkan dengan kristalisasi produk menggunakan metode hidrotermal pada suhu rendah [7-12].

\section{METODOLOGI}

Karakterisasi awal dilakukan untuk mengetahui komposisi kimia dari tailing bauksit. Metode analisis yang digunakan adalah X-Ray Spectroscopy (XRF). Metode sintesis dibagi menjadi dua tahapan, proses pertama disebut sebagai proses pra-sintesis dan yang kedua adalah proses sintesis produk. Proses pra-sintesis akan menghasilkan prekursor-prekursor baik alumina dan silika dalam bentuk garam yang metodenya dibagi menjadi dua yaitu: metode pelindian dan fusi kaustik. Sementara itu, proses sintesis produk merupakan tahapan untuk menghasilkan kristal zeolit dengan metode hidrotermal.

\section{Dekomposisi Tailing Bauksit Menggunakan Metode Fusi Kaustik}

Dekomposisi tailing bauksit melalui proses fusi kaustik menggunakan alkali sehingga membentuk garam-garam aluminat dan silikat. Alkali yang digunakan adalah $\mathrm{NaOH}$ padatan dari Merck. Proses dekomposisi dilakukan pada rasio massa tailing bauksit: yaitu $1: 1 ; 1: 1,5$; dan $1: 2$ (b/b), temperatur fusi $500{ }^{\circ} \mathrm{C}$ dan waktu fusi 90 menit menggunakan muffle furnace. Reaksi yang terjadi selama proses peleburan antara komponen $\mathrm{SiO}_{2}$ dan $\mathrm{Al}_{2} \mathrm{O}_{3}$ dengan $\mathrm{NaOH}$ adalah sebagai berikut [9]:
$2 \mathrm{NaOH}_{(\mathrm{s})}+\mathrm{Al}_{2} \mathrm{O}_{3(\mathrm{~s})} \rightarrow 2 \mathrm{NaAlO}_{2(\mathrm{~s})}+\mathrm{H}_{2} \mathrm{O}_{(\mathrm{g})}$

$2 \mathrm{NaOH}_{(\mathrm{s})}+\mathrm{SiO}_{2(\mathrm{~s})} \rightarrow 2 \mathrm{Na}_{2} \mathrm{SiO}_{3(\mathrm{~s})}+\mathrm{H}_{2} \mathrm{O}_{(\mathrm{g})}$

Produk hasil fusi kaustik, disebut sebagai frit, kemudian dilindi dengan air. Pelindian dengan air bertujuan untuk mendapatkan ekstrak $\mathrm{Si}$ dan $\mathrm{Al}$ terlarut dalam bentuk garam natrium silikat dan garam aluminat. Seperti cara konvensional, zeolit dibuat dari larutan gel silikat dan alumina silikat [13].

Pengadukan selama 1 jam kemudian dilakukan untuk mendapatkan campuran yang homogen dan sejumlah spesies $\mathrm{Si}$ dan $\mathrm{Al}$ yang terlarut. Campuran yang didapatkan disaring dengan menggunakan kertas saring, sehingga didapatkan residu serta filtrat. Volume filtrat yang didapatkan tidak akan sama dengan volume air yang ditambahkan pada saat proses aging karena sebagian volume air tersebut terserap oleh padatan fusi selama proses.

Filtrat yang didapat selanjutnya disebut ekstrak fusi yang mengandung spesies $\mathrm{Si}, \mathrm{Al}$, dan $\mathrm{Na}$ dianalisis menggunakan metode Atomic Absorption Spectroscopy (AAS). Ekstrak spesies Si dan Al terlarut ini akan digunakan sebagai gel awal (prekursor) pada proses selanjutnya yaitu perlakuan sol gel dengan menambahkan natrium silikat.

\section{Kristalisasi Produk Menggunakan Metode Hidrotermal}

Zeolit disintesis dari empat prekursor utama yaitu alumina, silika, $\mathrm{NaOH}$, dan air. Sumber alumina berasal dari tailing bauksit yang sudah diekstrak menjadi larutan supernatant (larutan kaya alumina) dan natrium silikat $\left(\mathrm{Na}_{2} \mathrm{SiO}_{3}\right)$ sebagai sumber silika. Rasio molar yang digunakan yaitu rasio $\mathrm{SiO}_{2} / \mathrm{Al}_{2} \mathrm{O}_{3}=1, \mathrm{H}_{2} \mathrm{O} / \mathrm{SiO}_{2}=10$, $\mathrm{Na}_{2} \mathrm{O} / \mathrm{SiO}_{2}=1,2$. Proses ini diawali dengan memasukkan larutan ekstrak ke dalam botol duran $250 \mathrm{~mL}$. 
Natrium silika selanjutnya dimasukkan secara perlahan tetes demi tetes dan aquades yang dibantu dengan pengadukan sehingga terbentuk semi gel. Botol duran yang berisi campuran tersebut diaduk selama 1 jam pada suhu ruang. Setelah homogen, botol duran dimasukan ke dalam oven dengan suhu 110$120{ }^{\circ} \mathrm{C}$ selama 2, 6, dan 12 jam. Endapan kemudian dicuci dengan air sampai $\mathrm{pH}$ netral (6-7) dan disaring. Setelah dicuci dan disaring, kemudian dimasukkan ke dalam oven pada suhu $110{ }^{\circ} \mathrm{C}$ selama 3 jam untuk mendapatkan padatan yang telah mengering dengan maksimal. Setelah dikeringkan, padatan putih kemudian digerus hingga halus dan dikarakterisasi menggunakan metode $X$ Ray Diffraction (XRD), Scanning Electron Microscopy-Energy Dispersive X-Ray Spectroscopy (SEM-EDS), dan BrunauerEmmett-Teller (BET).

\section{HASIL DAN PEMBAHASAN}

\section{Karakterisasi Tailing Bauksit}

Hasil analisis XRF untuk kareakterisasi awal menunjukkan unsur Al yang tinggi hingga 26,15\%, Si sebesar 5,88\% dan $\mathrm{Fe}$ sebesar $7,02 \%$ sebagai unsur mayor dalam tailing bauksit sedangkan dalam bentuk senyawanya dapat dilihat pada Tabel 1.

Tabel 1. Komposisi tailing bauksit.

\begin{tabular}{lccccc}
\hline Komposisi & $\begin{array}{c}\mathrm{Al}_{2} \mathrm{O}_{3} \\
(\%)\end{array}$ & $\begin{array}{c}\mathrm{SiO}_{2} \\
(\%)\end{array}$ & $\begin{array}{c}\mathrm{Fe}_{2} \mathrm{O}_{3} \\
(\%)\end{array}$ & $\begin{array}{c}\mathrm{TiO}_{2} \\
(\%)\end{array}$ & $\begin{array}{c}\text { Lainnya } \\
(\%)\end{array}$ \\
\hline $\begin{array}{l}\text { Tailing } \\
\text { Bauksit }\end{array}$ & 49,41 & 12,58 & 10,06 & 1,10 & 26,85 \\
\hline
\end{tabular}

Analisis XRD menunjukkan unsur utama dalam tailing bauksit didominasi oleh Al dan Si. Sedangkan pengotor utama dalam bentuk $\mathrm{Fe}$, Ti, dan logam lainnya dalam konsentrasi rendah.

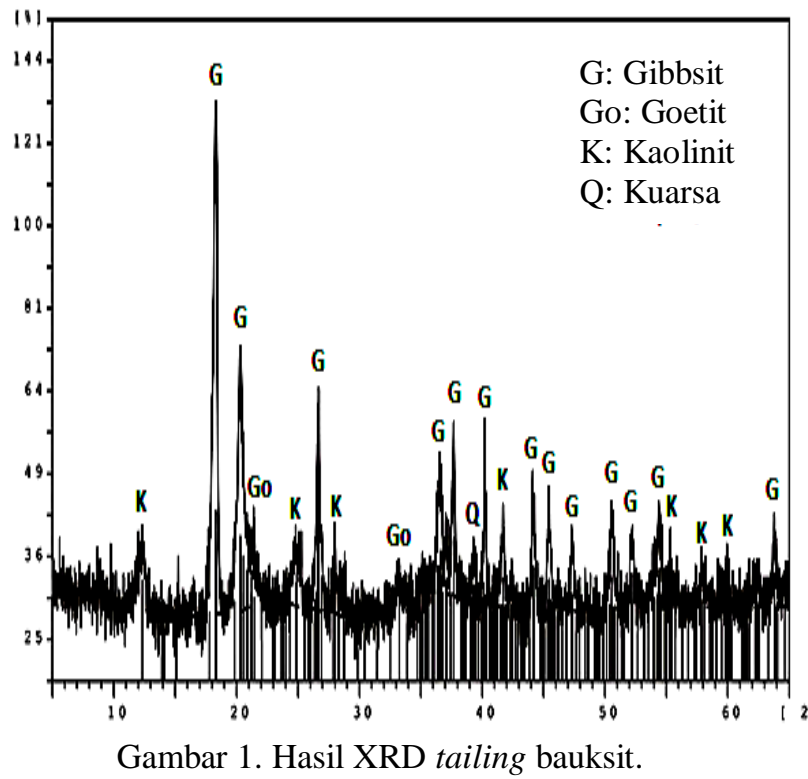

Gambar 1 menunjukkan bahwa tailing bauksit merupakan produk samping (byproduct/waste) yang berasal dari hasil proses benefisiasi bauksit tersebut mengandung gibbsit $(\mathrm{G})$, kaolinit (K) yang dominan dan beberapa mineral goetit (Go) dan kuarsa (Q).

\section{Fusi Alkali}

Ada 3 (tiga) kunci variabel dalam proses fusi kaustik yaitu temperatur fusi, waktu fusi, dan rasio masa tailing bauksit/ $\mathrm{NaOH}$ yang secara signifikan mempunyai pengaruh atau efek dalam kapasitas kelarutan $\mathrm{Al}_{2} \mathrm{O}_{3}$ dan $\mathrm{SiO}_{2}$ [14].

Proses fusi alkali bertujuan untuk mengaktifkan komponen utama $\mathrm{Si}$ dan $\mathrm{Al}$ pada tailing menjadi fase mineral yang larut dalam air yaitu natrium silikat dan natrium aluminat dan silikat alumino amorf.

Struktur kristalin yang diperoleh dari hasil XRD akan digunakan sebagai kriteria untuk mengetahui pembentukan aluminat terlarut dan silika terlarut. Gambar 2 menunjukkan pembentukan fasa mulai dari rentang $2 \theta$ yaitu $10-80^{\circ}$ dengan fasa yang terbentuk adalah $\mathrm{NaAlO}_{2}$ yang dominan dan beberapa $\mathrm{Na}_{2} \mathrm{SiO}_{3}, \mathrm{NaOH}$, dan $\mathrm{FeFe}_{2} \mathrm{O}_{4}$. 


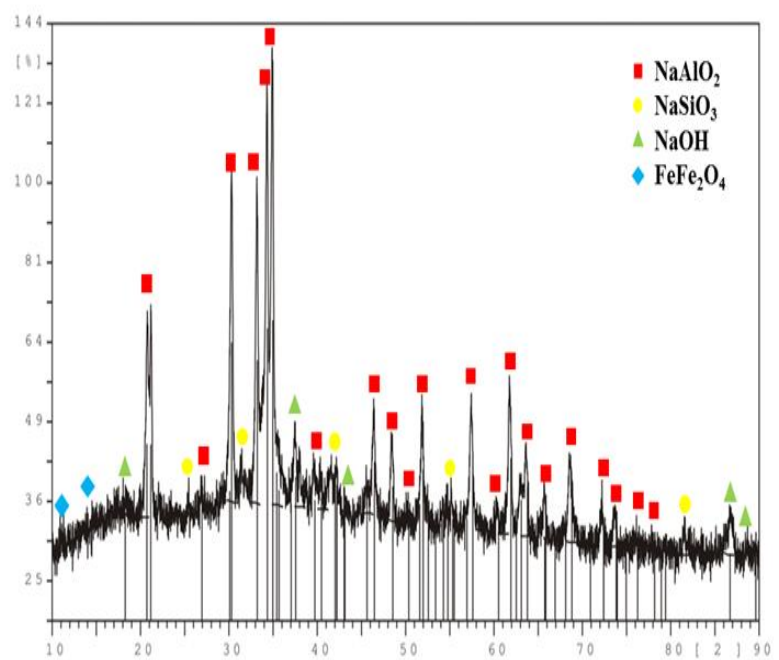

Gambar 2. XRD hasil reaksi fusi kaustik.

Tailing bauksit yang telah melalui proses fusi kaustik strukturnya akan berbentuk kasar. Hal ini sesuai dengan Gambar 3 yang menunjukkan morfologi tailing bauksit sesudah dilakukan fusi kaustik dengan $\mathrm{NaOH}$.

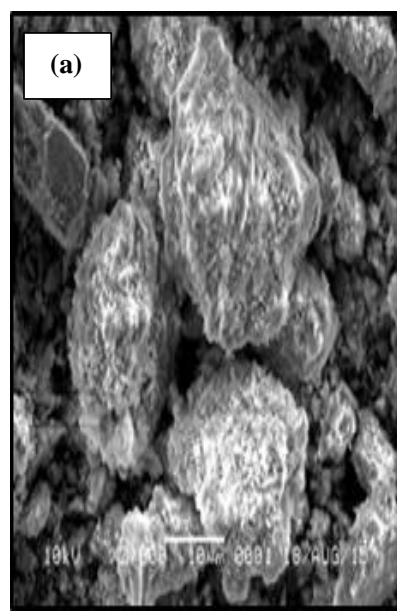

Gambar 3. Tailing bauksit fusi dengan $\mathrm{NaOH}$.

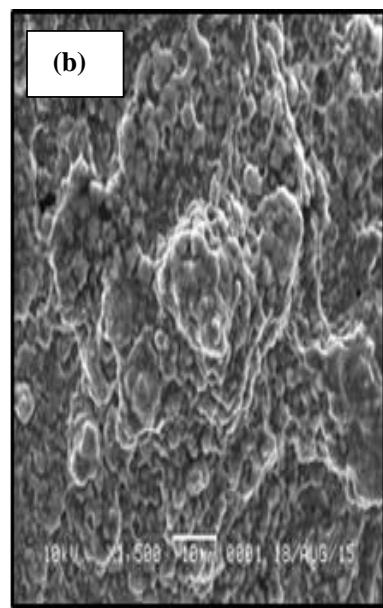

(a) murni dan (b) setelah
Mekanisme yang terjadi pada saat fusi kaustik dimulai dari penyerangan awal $\mathrm{NaOH}$ terhadap permukaan tailing bauksit yang akan merusak rantai silika dan alumina. Kemudian partikel-partikel yang terdapat dalam tailing bauksit keluar sedangkan alkali akan masuk ke dalam tailing bauksit dengan membentuk produk-produk antara garam silika dan aluminat. Produk reaksi yang dihasilkan akan memenuhi lapisan mineral baik di dalam maupun di luar permukaannya, hingga hampir semua partikel mineral tersebut terkonsumsi dan bereaksi dengan $\mathrm{NaOH}$. Hal ini mengakibatkan produk reaksi atau padatan fusi akan terbentuk seperti endapan pejal yang akan menutupi permukaan mineral. Endapan seperti kerak ini akan menyebabkan permukaan mineral tersebut menjadi kasar (Gambar 4)

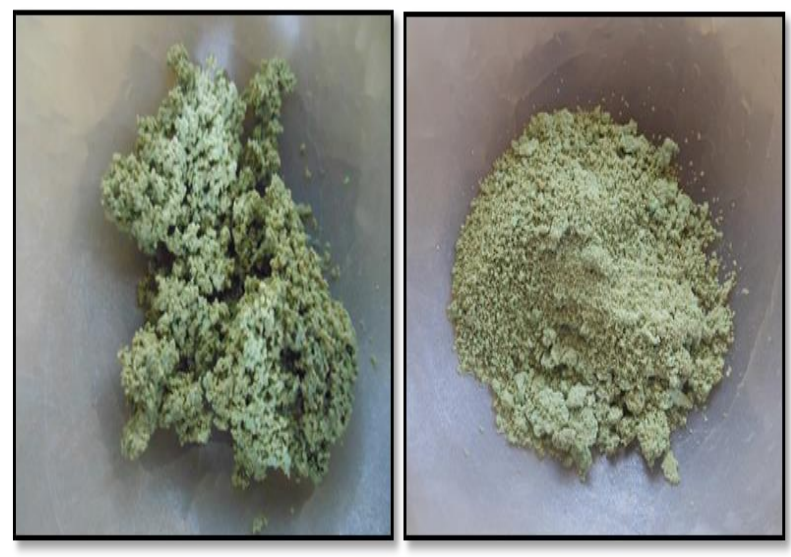

Gambar 4. Hasil fusi kaustik tailing bauksit $+\mathrm{NaOH}$.

\section{Kristalisasi Zeolit Adsorben Menggunakan} Metode Hidrotermal Temperatur Rendah

Proses kristalisasi produk menggunakan metode hidrotermal pada temperatur rendah yaitu $90-120{ }^{\circ} \mathrm{C}$ selama 2 , 6, dan 12 jam waktu inkubasi. Rasio molar yang digunakan adalah $1,2 \mathrm{Na}_{2} \mathrm{O} \cdot 0,5 \mathrm{SiO}_{2} . \quad 0,5 \mathrm{Al}_{2} \mathrm{O}_{3} . \quad 10 \mathrm{H}_{2} \mathrm{O}$. Formulasi rasio molar dapat dilihat pada Tabel 2, sementara komposisi produknya dapat dilihat pada Tabel 3 .

Tabel 2. Formulasi rasio molar produk zeolit adsorben

\begin{tabular}{lcccc}
\hline Komposisi & $\mathbf{S i O}_{2}$ & $\mathbf{H}_{2} \mathbf{O}$ & $\mathbf{A l}_{2} \mathbf{O}_{3}$ & $\mathbf{N a}_{2} \mathbf{O}$ \\
\hline Molar & 0,5 & 10,0 & 0,5 & 1,2 \\
$\mathrm{MW}(\mathrm{g} / \mathrm{mol})$ & 60 & 18 & 102 & 62 \\
$\rho(\mathrm{g} / \mathrm{ml})$ & - & - & - & - \\
$\mathrm{W}(\mathrm{g})$ & 30 & 180 & 51 & 74 \\
\hline
\end{tabular}


Tabel 3. Komposisi produk zeolit adsorben

\begin{tabular}{lccccc} 
Material & $\begin{array}{c}\boldsymbol{\rho} \\
(\mathbf{g} / \mathbf{m l})\end{array}$ & $\begin{array}{c}\text { Purity } \\
(\boldsymbol{\%})\end{array}$ & $\begin{array}{c}\text { MW } \\
(\mathbf{g} / \mathbf{m o l})\end{array}$ & $\begin{array}{c}\text { Massa Volume } \\
(\mathbf{g})\end{array}$ & $(\mathbf{m L})$ \\
\hline $\mathrm{Al}_{2} \mathrm{O}_{3}$ fusi & - & 51,22 & 102,00 & - & - \\
$\mathrm{Na}_{2} \mathrm{SiO}_{3}$ & 1,35 & 100,00 & 122,00 & 54,10 & 40,10 \\
$\mathrm{H}_{2} \mathrm{O}$ & - & - & 18 & 180 & 180 \\
\hline
\end{tabular}

Proses sintesis dimulai dengan menuangkan larutan ekstrak ke dalam botol $250 \mathrm{ml}$. Natrium silika diteteskan perlahanlahan sehingga membentuk semi gel (Gambar 5). Kemudian larutan diaduk dan diendapkan maka sehingga didapatkan endapan kristal (Gambar 6). Endapan kristal dimasukkan dalam oven dan menghasilkan padatan yang mengering kemudian digerus hingga halus (Gambar 7).

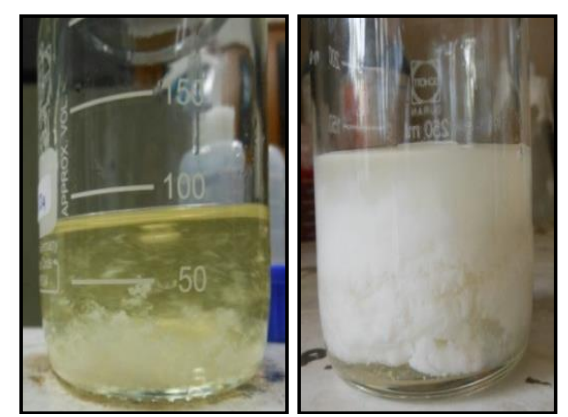

Gambar 5. Proses pembentukan sol gel.

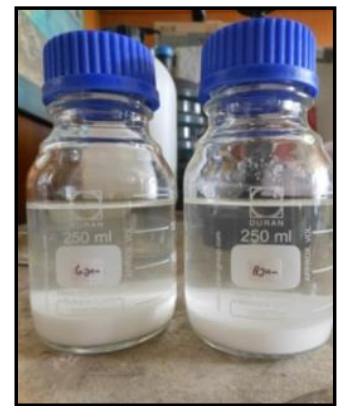

Gambar 6. Proses kristalisasi.
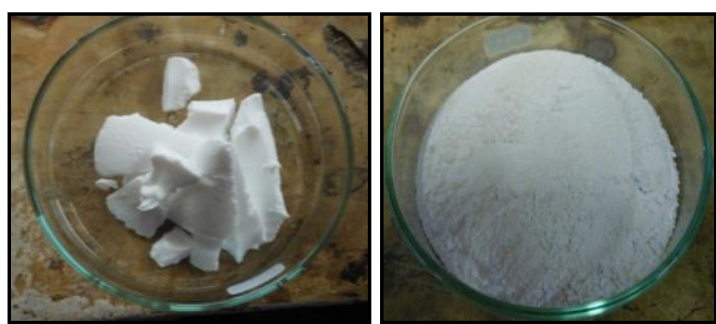

Gambar 7. Produk zeolit adsorben.
Berdasarkan pola XRD, pembentukan struktur kristal yang terbentuk adalah fasa zeolit Na-P1. Pola difraksi yang dihasilkan memiliki kesesuaian atau kemiripan dengan pola difraksi zeolit Na-P1 standar. Kesesuaian tersebut ditunjukkan pada kelima puncak yang sama dengan zeolit Na-P1 standar pada puncak $2 \theta$ sama dengan 12,$5 ; 17,7 ; 21,7$; 28,2 ; dan $33,5^{\circ}$.
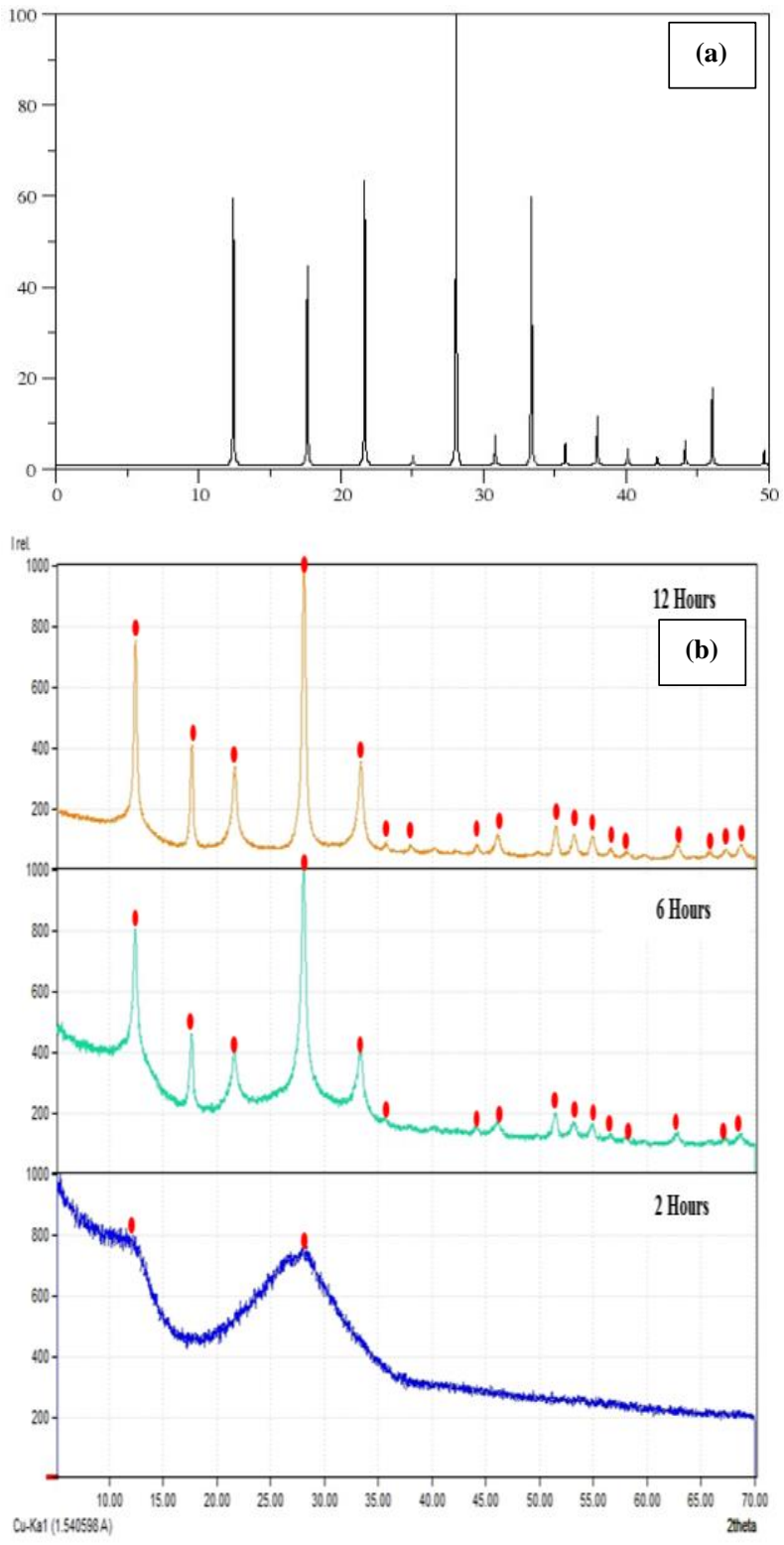

Gambar 8. Hasil XRD zeolit standar Na-P1 (a) dan zeolit sintesis (b) menunjukkan transformasi dari fasa amorf ke fasa kristalin. 
Berdasarkan hasil difraktogram, pola difraksi sinar-X menunjukkan pembentukan kristal zeolit Na-P1. Fasa amorf mulai terbentuk hingga fasa kristalin. Perubahan fase ini menandakan bahwa seiring dengan lamanya waktu inkubasi, ketika proses induksi (waktu antara awal reaksi sampai produk kristal pertama kali teramati) inti berkembang dan kemudian tumbuh dengan cepat menjadi kristal berukuran kecil dan seragam. Munculnya puncak-puncak pola difraksi menandakan bahwa kristal mulai terbentuk.

Hasil analisis morfologi SEM zeolit NaP1 menunjukkan perubahan dari fasa amorf menjadi fasa berukuran kristal (Gambar 9). Hal ini membuktikan bahwa kristal tumbuh dari kecil menjadi besar dan berkembang membentuk struktur yang seragam. Pertumbuhan kristal diartikan sebagai suatu proses bertambahnya ukuran atau volume kristal atau bobot kristal.
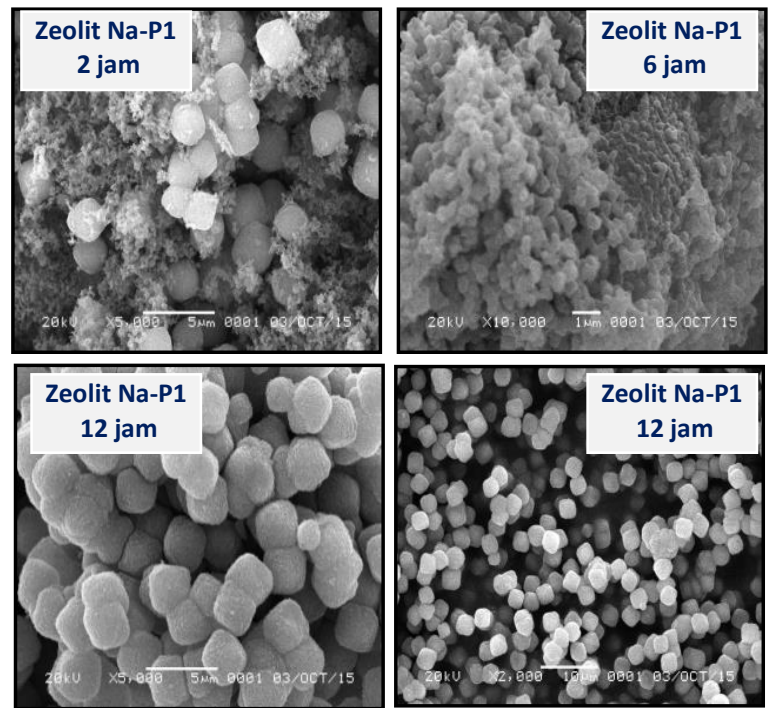

Gambar 9. Morfologi produk kristalisasi zeolit adsorben dari 2, 6, dan 12 jam.

Berdasarkan kurva isotermal adsorpsidesorpsi menggunakan analisis BET (Gambar 10), terbentuk kurva isotermal dengan tipe IV yang menjelaskan formasi dari lapis tunggal yang diikuti oleh lapis ganda. Tipe ini diperoleh dari mesopori pada adsorben. Umumnya kurva isotermal tipe IV sering diasosiasikan dengan kondensasi kapiler. Kondensasi ini berlangsung pada mesopori yang memiliki histeris loop dengan ukuran pori dalam rentang 15-1000 A.

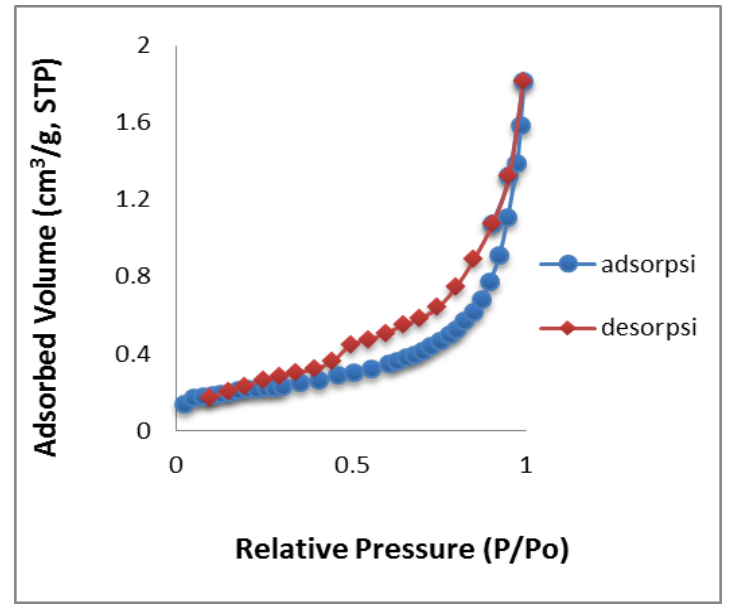

Gambar 10. Kurva isoterm adsorpsi-desorpsi.

Standar ukuran pori yang menggunakan International Union of Pure and Applied Chemistry (IUPAC), mengklasifikasikan pori berdasarkan rentang ukurannya. Rentang kuran tersebut yaitu: pori dengan ukuran kurang dari $2 \mathrm{~nm}$ disebut mikropori; ukuran pori dalam rentang 2-50 $\mathrm{nm}$ disebut sebagai mesopori; dan pori dengan ukuran lebih dari $50 \mathrm{~nm}$ disebut sebagai makropori. Zeolit NaP1 hasil sintesis pada kondisi terbaik menghasilkan ukuran rerata pori sebesar $16,122 \mathrm{~nm}$ dengan lus permukaan $8,996 \mathrm{~m}^{2} / \mathrm{g}$. Zeolit Na-P1 dalam kondisi terbaik dikategorikan ke dalam mesopori. Karakteristik pori dapat dilihat pada Tabel 3.

Tabel 3. Ukuran pori dari produk terbaik adsorben.

\begin{tabular}{lc}
\multicolumn{1}{c}{ Parameter } & Produk Zeolit Na-P1 \\
\hline Ukuran pori rata-rata $(\mathrm{nm})$ & 16,122 \\
Area permukaan $\left(\mathrm{m}^{2} / \mathrm{g}\right)$ & 8,996 \\
Total volume pori $(\mathrm{cc} / \mathrm{g})$ & $3,626 \times 10^{-2}$ \\
\hline
\end{tabular}




\section{KESIMPULAN}

Tailing bauksit dapat diekstraksi menggunakan metode fusi kaustik dengan $\mathrm{NaOH}$. Tailing bauksit dapat menjadi sumber prekursor alumina yang baik dalam melakukan sintesis zeolit adsorben melalui proses kristalisasi pada suhu rendah dan di bawah tekanan atmosfer. Kedua proses tersebut telah berhasil mengubah produk dari fase amorf ke fase kristal yaitu berupa zeolit adsorben jenis Na-P1 dengan tingkat kemurnian yang tinggi $>90 \%$ (\% kristalinitas) serta memiliki luas permukaan $8,996 \mathrm{~m}^{2} / \mathrm{g}$, ukuran pori rata-rata $16,122 \mathrm{~nm}$ dan morfologi kristal berbentuk kubik.

\section{UCAPAN TERIMA KASIH}

Ucapan terima kasih dari Tim Peneliti kepada DP2M Dikti, Direktur, dan Ketua P3KM Politeknik Negeri Ketapang beserta jajarannya yang telah mengizinkan Kami turut berpartisipasi dalam hibah Penelitian Dosen Pemula (PDP).

\section{DAFTAR PUSTAKA}

[1] P. Smith, "The Processing of High Silica Bauxites - Review of Existing and Potential Processes," Hydrometallurgy, vol. 98, no. 1, pp. 162-176, 2009.

[2] H. Yang, C. Chen, H. Sun, H. Lu, and X. Hu, "Influence of Heat-Treatment Schedule on Crystallization and Microstructure of Bauxite Tailing Glass-Ceramics Coated on Tiles," $J$. Mater. Process. Technol., vol. 197, no. 1, pp. 206-211, 2008.

[3] D. Yang, N. Feng, Y. Wang, and X. Wu, "Preparation of Primary Al-Si Alloy from Bauxite Tailings by Carbothermal Reduction Process," Trans. Nonferrous Met. Soc. China, vol. 20, no. 1, pp. 147-152, 2010.

[4] H. Yang, C. Chen, L. Pan, H. Lu, H. Sun, and X. $\mathrm{Hu}$, "Preparation of Double-Layer GlassCeramic/Ceramic Tile from Bauxite Tailings and Red Mud," J. Eur. Ceram. Soc., vol. 29, no. 10, pp. 1887-1894, 2009.

[5] R. F. Lobo, "Introduction to the Structural Chemistry of Zeolites," in Handbook of Zeolite Science and Technology, CRC Press, 2003, pp. 92-124.

[6] X. Meng and F.-S. Xiao, "Green Routes for Synthesis of Zeolites," Chem. Rev., vol. 114, 2013.

[7] N. Shigemoto, H. Hayashi, and K. Miyaura, "Selective Formation of $\mathrm{Na}-\mathrm{X}$ Zeolite from Coal Fly Ash by Fusion with Sodium Hydroxide Prior to Hydrothermal Reaction," J. Mater. Sci., vol. 28, pp. 4781-4786, 1993 .

[8] A. Singer and V. Berkgaut, "Cation Exchange Properties of Hydrothermally Treated Coal Fly Ash," Environ. Sci. Technol., vol. 29, no. 7, pp. 1748-1753, 1995.

[9] K. Ojha, N. C. Pradhan, and A. N. Samanta, "Zeolite from Fly Ash: Synthesis and Characterization," Bull. Mater. Sci., vol. 27, no. 6, pp. 555-564, Dec. 2004.

[10] A. Molina and C. Poole, "A Comparative Study Using Two Methods to Produce Zeolites from Fly Ash," Miner. Eng., vol. 17, no. 2, pp. 167-173, 2004.

[11] Y. Yanti, "Sintesis Zeolit-A dan Zeolit Karbon Aktif dari Abu Dasar PLTU Paiton dengan Metode Peleburan," Institut Teknologi Sepuluh Nopember, 2009.

[12] D. Ma, Z. Wang, M. Guo, M. Zhang, and J. Liu, "Feasible Conversion of Solid Waste Bauxite Tailings into Highly Crystalline 4A Zeolite with Valuable Application," Waste Manag., vol. 34, no. 11, pp. 2365-2372, 2014.

[13] R. M. Barrer, "Hydrothermal Chemistry of Zeolites," in Zeolite Synthesis, M. L. Occelli and H. E. Robson, Eds. Washington DC: Louisiana State University, 1989.

[14] Z. D. Wang, M. Guo, and M. Zhang, "Synthesis and Characterization of Zeolite 4A from Bauxite Tailings," in The 2012 National Conference on Physical Chemistry of Metallurgy, 2012. 